\title{
The Nature of Domestic Violence against of Children in Saudi Arabia Systematic Literature Review
}

Aref Alsehaimi ${ }^{1 *}$ and Abdullah Alanazi ${ }^{2}$

${ }^{1}$ University of Dundee, UK

2University of Hail, Saudi Arabia

\begin{abstract}
Until recently, the subject of child abuse in Saudi Arabia received very little attention. It was only in the 1990s that cases of child abuse and neglect began to be reported by the Saudi medical profession. A comprehensive, systematic review of the published literature available since that time is presented here. The paucity of research conducted to date is reflected in the fact that only nine articles were found that satisfied the selection criteria, plus four others identified through a search of grey literature. An appraisal tool was used to assess the quality of these studies. The relevant work that has been published indicates that child abuse, of various types, exists within Saudi Arabia but the research does not provide sufficient statistical evidence to be able to determine the extent of the problem. However, there are indications in the published literature of some of the factors that may contribute to child abuse in the Kingdom. These include cultural and societal attitudes, and income and educational levels of parents. Another contributing influence on child abuse in Saudi Arabia appears to be the lack of legislation or legal clarity to protect the rights of minors. Although the review found that there are some government and private initiatives aimed at addressing the issue, these remain inadequate because no formal unifying organization yet exists. A summary of the findings and their implications is followed by a discussion of where further research is needed to fill the gaps in present knowledge of the child abuse problem in Saudi Arabia. Recommendations for future work are made in the hope that this will lead to increased awareness of this important and long-neglected issue among professionals and public alike.
\end{abstract}

Keywords: Saudi Arabia; Child abuse; Domestic violence

\section{Introduction}

Child abuse, in its various forms, is now universally recognized as being a worldwide phenomenon [1]. However, open discussion of it is problematic in conservative societies [2] and it was not until the 1990s that cases of child abuse and neglect began to be reported by medical professionals in Saudi Arabia [3]. However, at that time there were no government guidelines in place to help medical personnel in dealing with such cases, nor any national system set up for collecting and analyzing data on abuse [4]. Some researchers argued that the absence of a legal system to deal with this issue was a major contributing factor to the lack of documented cases and that there was a pressing need to introduce child protection laws and procedures to protect children and respond to their abuse [5-8]. It was only in 2004, with the establishment of the National Society for Human Rights (NSHR), that government policies began to be put in place to give some measure of protection to children against abuse [9]. However, there is still no penal code that is consistently adhered to.

Both the society and the legal system of Saudi Arabia are underpinned and dominated by Islamic law [10]. Islam lays stress on the rights of children in areas such as education, nutrition, and health care. For this reason, the Kingdom of Saudi Arabia provides free education and health care for everyone, with an emphasis on catering for the needs of children [11]. Islamic law also makes statements about the disciplining, including the physical disciplining, of children. For example, under certain conditions, it allows and even advocates the use by parents of a stick to beat their children. Thus moderate beatings are regarded as normal and acceptable at home and also in schools, where teachers are often granted the right by parents to beat their children in their stead [12]. Even these common and moderate beatings, allowed within Islamic law, would be considered abusive under many Western jurisdictions. However, more seriously, the social acceptability of such treatment of children contributes to a climate and culture in which further and more extreme physical abuse may take place, in the home, school, and elsewhere [12].

There have been many attempts to define "child abuse"; definitions have changed over time and may vary from place to place [13]. Many studies identify four categories of abuse: physical, emotional, sexual, and neglect $[2,13]$. The definition of child abuse adopted by the United Nations (2006:35) [14] refers to any act that may cause harm of any kind to the victim, including: "all forms of physical or mental violence, injury and abuse, neglect or negligent treatment, maltreatment or exploitation, including sexual abuse".

Certain aspects of child abuse are extremely sensitive topics in Saudi society because of what Islamic law has to say about them. Discussion of sexual abuse, for example, has traditionally been taboo. The other forms of abuse, too, have not been discussed openly, until recently, due to the conservative nature of the country, the inherent tribalism of the culture, and the overarching power of Islamic teachings on the subject. High profile cases of extreme abuse that have been reported in the media over the past 20 years, together with documented medical reports by physicians in hospitals, have raised public and professional awareness of the issue.

\section{Aims}

The primary aim of this study is to conduct a comprehensive review of published literature on child abuse in Saudi Arabia in order to ascertain what is known about the nature and extent of the phenomenon. From these findings, recommendations will be made for future practice and research in the field, which may ultimately be of use to policy makers and social workers who deal with cases of child abuse. Among secondary aims are to identify: (1) the prevalence

${ }^{*}$ Corresponding author: Aref Alsehaimi, University of Dundee, UK: E-mail: a.alsehaimi@dundee.ac.uk

Received May 13, 2015; Accepted September 04, 2015; Published September 11,2015

Citation: Alsehaimi A, Alanazi A (2015) The Nature of Domestic Violence against of Children in Saudi Arabia Systematic Literature Review. J Psychol Abnorm Child 4: 146. doi:10.4172/2329-9525.1000146

Copyright: (c 2015 Alsehaimi A, et al. This is an open-access article distributed under the terms of the Creative Commons Attribution License, which permits unrestricted use, distribution, and reproduction in any medium, provided the original author and source are credited. 
of different types of child abuse; (2) the actions and policies being adopted by the government to address the problem; and (3) explore the underlying causes of child abuse in Saudi Arabia and, in particular, the role that Islamic law has in both protecting the rights of children and contributing to a culture in which abuse may be encouraged.

\section{Methodology}

The method used in this study is a systematic review. The approach employed has been adapted from that of the NHS Centre for Reviews and Dissemination 2001 (CRD). It involves five phases, the first of which is to establish the inclusion and exclusion selection criteria. These criteria were determined by the main aim of the study, which is to establish what is known about the nature and extent of child abuse in Saudi Arabia, and, beyond this, to ascertain what official steps have been taken to address the issue. The selection criteria used in this study are shown in Table 1. In total, following the searches and application of selection criteria, 13 sources were identified as being relevant to this study. The quality of these sources was assessed by examining their relevance to the main aim of the research, their methodological value, and any effect due to biasing.

\begin{tabular}{|c|c|c|}
\hline Selection criteria & Inclusion criteria & Exclusion criteria \\
\hline Language & English and Arabic & Other \\
\hline Publication date & Published from 1990 onwards & Published prior to 1989 \\
\hline Search in & $\begin{array}{l}\text { Complete journal articles and } \\
\text { thesis. }\end{array}$ & Articles with abstracts only \\
\hline Selection criteria & Inclusion criteria & Exclusion criteria \\
\hline $\begin{array}{l}\text { Conditions of } \\
\text { interest }\end{array}$ & $\begin{array}{l}\text { Studies concerned with } \\
\text { children who have suffered } \\
\text { from any kind of domestic } \\
\text { violence (neglect, sexual, } \\
\text { physical, etc.) }\end{array}$ & $\begin{array}{l}\text { Studies discussing cases of } \\
\text { child abuse outside the family } \\
\text { Case reports which do not } \\
\text { include discussion Studies } \\
\text { on the health problems that } \\
\text { accompany family violence. }\end{array}$ \\
\hline $\begin{array}{l}\text { Geographical } \\
\text { coverage }\end{array}$ & Saudi Arabia & Other countries \\
\hline Study design & Any design & - \\
\hline
\end{tabular}

\section{Results and Discussion}

This study has revealed a deficiency of published work about child abuse in Saudi Arabia, even though the existence of the problem became apparent more than two decades ago [3]. Various reasons have been put forward for this lack of documentation. Elkerday et al. [6] and Roy et al. [8] point to inexperience or lack of knowledge of physicians in dealing with abuse cases. Others, such as Al-Angari [9] blame the lack of visibility or discussion of the problem in conservative Saudi society. For the period 1990-2005, the literature research revealed only 39 cases of child abuse, 18 of which were categorized as physical abuse and 7 as sexual abuse [15].

This is no way reflects the true scale of the problem in a total Saudi population of more than 25 million. However, the initial medical reports of abuse, together with coverage of specific abuse cases in the national media, did at least serve to raise public and governmental awareness of the issue. In 2006, the first official report on child abuse, by the General Directorate of Social Protection, indicated that 510 cases of abuse had come to the attention of social protection committees in 2006.

A variety of causative factors have been suggested for abuse in Saudi Arabia. The apparent preponderance of physical abuse has been partly accounted for by a culture in which corporal punishment in the home is a widely accepted form of disciplining [16]. Another factor that has been suggested is when there is big discrepancy in age, especially due to marriage between young girls and much older men, or educational level between spouses [4]. Several studies claim that such non-parity can be a contributing factor to Saudi domestic violence $[17,18]$. A link between maternal illiteracy and emotional and physical neglect was found by [17], who also reported that an educated father with an illiterate spouse was more likely to neglect his child emotionally and physically. It was pointed to a connection between low income and risk of abuse, and $\mathrm{Al}-$ Mahroos (2007) [18] found that the highest fatality rates in child abuse cases occurred among poor people. Al-Brithen (2006) [19] reported a significant link between alcohol consumption and domestic violence (Tables 2 and 3).

\begin{tabular}{|c|c|c|c|c|}
\hline \multirow{2}{*}{ Name of Electronic Journal } & \multirow{2}{*}{ Journal Articles Covering Violence in Saudi Arabia } & \multicolumn{2}{|c|}{ Relevant } & \multirow{2}{*}{ Total } \\
\hline & & Yes & No & \\
\hline Journal of Interpersonal Violence & Attitudes of Arab Women Toward Different Patterns of Coping With Wife Abuse. (Haj-Yahia) & & * & 1 \\
\hline $\begin{array}{l}\text { Child Abuse and Neglect: The } \\
\text { International Journal }\end{array}$ & Defining Abuse Cross-Culturally: From Failure to Keep a Clean House of Physical Abuse. (Malley) & & * & 1 \\
\hline Gulf Area Office, UNICEF & Child Protection, presented by Combating Child Trafficking Workshop organized by UNICEF and Naif Arab University & & * & 1 \\
\hline \multirow[t]{7}{*}{ Annals of Saudi Medicine } & Subcutaneous Fat Necrosis as an Unusual Presentation of Child Abuse. (Kattan et al.) & * & & \multirow{7}{*}{7} \\
\hline & Child Abuse and Neglect in Saudi Arabia: What Are We Doing and Where Do We Stand? (Al-Eissa) & * & & \\
\hline & The Spectrum of Child Abuse Presenting to a University Hospital in Riyadh. (Al-Ayed et al.) & * & & \\
\hline & Child Abuse and Neglect: Perspective from King Faisal Specialist Hospital and Research Centre. (Kattan) & * & & \\
\hline & Rhabdomyolysis and Acute Renal Failure in a Case of Child Abuse. (Roy et al.) & * & & \\
\hline & Fatal Physical Child Abuse in Two Children of Family. (Elkerdany et al.) & * & & \\
\hline & Child Abuse: Report of Three Cases from Khamis Mushayt. (Karthikeyan et al.) & * & & \\
\hline \multirow[t]{2}{*}{ Saudi Trends Journal } & Municipal Council for Children (News) & & * & \multirow{2}{*}{2} \\
\hline & Committee to Address Woman and Child Abuse (News) & & * & \\
\hline \multirow[t]{3}{*}{ Saudi Trends Journal } & Family Status Authority to be established (News) & & * & \multirow{3}{*}{3} \\
\hline & Law on Violence Against Women and Children (News) & & * & \\
\hline & Child Abuse and Neglect in the Arab Peninsula. (Al-Mahroos) & * & & \\
\hline $\begin{array}{l}\text { Umm Al-Qura University Journal of } \\
\text { Education, Social \& Humanitarian } \\
\text { Science }\end{array}$ & The Impact of Family Violence on Deviant Behaviours of Girls in Intermediate Schools in Makkah City. (Al-Qarni) & * & & 1 \\
\hline International Journal of Dermatology & Lichen Sclerosis Mistaken for Child Sexual Abuse. (Al-Khenaizan et al.) & & * & 1 \\
\hline
\end{tabular}

Table 2: Articles found dealing with domestic abuse in Saudi Arabia. 


\begin{tabular}{|l|c|c|}
\hline Title of Research & Relevant & Source \\
\hline Alcoholism and Domestic Violence in Saudi Society & No & COPAC \\
\hline $\begin{array}{l}\text { Child Abuse and Neglect: Its Causes and Consequences in } \\
\text { the Kingdom of Saudi Arabia }\end{array}$ & Yes & COPAC \\
\hline $\begin{array}{l}\text { Child abuse in Riyadh: Curses, Forms and the Characters } \\
\text { of Victims }\end{array}$ & Yes & KFNL \\
\hline How to deal with the problem of child abuse in Saudi Arabia & Yes & KFNL \\
\hline $\begin{array}{l}\text { Domestic violence: Causes, effects and results in the } \\
\text { Kingdom of Saudi Arabia }\end{array}$ & Yes & KFNL \\
\hline
\end{tabular}

Table 3: Theses and Dissertations Identified from Main Search.

Efforts at government level to deal with the problem of child abuse have been limited. One of the earliest was a program set up at the King Faisal Specialist Hospital and Research Centre (KFSH\&RC)[20], which is designed to detect, report, and prevent child abuse and is modeled upon child protection policies used in the United States [7].

\section{Recommendations}

Based on this review of literature available on child abuse in Saudi Arabia, the author makes the following primary recommendation: that a national center for social studies, subordinate to the Ministry of Social Affairs, be established to coordinate the efforts of other institutions in the country dealing with this problem. This national center would:

Set up a uniform process for other institutions to follow when handling cases of abuse. This would include establishing a national database through which diverse and specialist organizations in the field could share information.

$\square$ Implement family courts to preside over cases of abuse, which would include social workers, physicians, psychologists, and security officials working in cooperation.

$\square$ Establish a national helpline that can be accessed by children.

$\square$ Ensure that all those dealing with cases of child abuse, including police and courts, provide protection and privacy for the victims.

Oversee training of professionals who deal with child abuse as to how to detect cases of violence and what actions are to be taken in such cases.

The study also revealed that a major potential source of child abuse in Saudi Arabia is the excessive use of corporal punishment as a means of child-rearing. The researcher thus recommends action in the following areas:

Setting up awareness programs, under the supervision of specialists, to educate families on appropriate methods of raising children.

$\square \quad$ Introducing into school curricula advice for children on how to get help in the event of they are abused by anyone, inside or outside the family.

$\square$ Appealing to imams to help the community understand the position of Islam on violence and the need for moderation when disciplining children.

\section{Conclusion}

Saudi Arabia is a socially and culturally conservative country that has only recently begun to confront its indigenous problem of domestic child abuse, the scale of which has yet to be properly determined. As this study makes clear, little has been published on the subject and there is need of a national database and social research centre to coordinate activities in the field.
Numerous factors, the research has indicated, underlie child abuse in Saudi society, including the ubiquity of corporal punishment of children, low levels of parental education and income, and large disparity in ages between spouses especially when due to an early marriage of the female.

The lack of legislation in the Kingdom to protect children from abuse remains a problem. Recommendations have made, both for the community and decision-makers in the State, to begin to address the issue and find appropriate solutions that are workable within the culture of Saudi Arabian society.

\section{References}

1. Gilbert R, Widom CS, Browne K, Fergusson D, Webb E, et al. (2009) Burden and consequences of child maltreatment in high-income countries. Lancet 373 : 68-81.

2. Corby B (2006) Child Abuse: Towards Knowledge Base, Maidenhead: Open University Press.

3. Al Eissa Y (1998) Child Abuse and Neglect in Saudi Arabia: What are we doing and where do we stand. Annals of Saudi Medicine 18: 105-110.

4. Al Youssef A (2005) Domestic violence: Causes, effects and results in Kingdom of Saudi Arabia. The Ministry of Social Affairs. Saudi Arabia.

5. Al Ayed (1998) The Spectrum of Child Abuse Presenting to a University Hospita in Riyadh. Annals of Saudi Medicine 18: 125-131.

6. Elkerdany (1999) Fatal Physical Child Abuse in Two Children of Family. Annals of Saudi Medicine 19: 120-123.

7. Kattan H (1998) Child Abuse and Neglect: Perspective from King Faisa Specialist Hospital and Research Centre. Annals of Saudi Medicine 18: 107109

8. Roy (1999) Rhabdomyolysis and Acute Renal Failure in a Case of Child Abuse. Annals of Saudi Medicine 19: 248-250.

9. Al Angari S (2004) How to deal with the problem of child abuse in Saudi Arabia. Centre for Research on Crime: Interior Ministry. Riyadh.

10. Al Qarni M (2005) The Impact of Family Violence on Deviant Behaviours of Girls in Intermediate Schools in Makkah City. Umm AIQura University. Journal of Education, Social and Humanitarian Science, 17: 18-28.

11. The Saudi Ministry of Education (2000) Annual Report for Ministry of Education in Saudi Arabia "The Future of Education in Saudi Arabia".

12. Alanazi N (2008) The use of physical punishment on children in Saudi Arabia: Perceptions and experiences of parents and young people, Durham University.

13. Unicef, Al-Azha University (2005) Children in Islam: Their Care, Development and Protection.

14. United Nations (2006) Rights of the child. Promotion and protection of the rights of children.

15. Al Khenaizan S (2004) Lichen Sclerosis Mistaken for Child Sexual Abuse. International Journal of Dermatology 44: 317-320.

16. Karthikeyan (2000) Child Abuse: Report of Three Cases from Khamis Mushayt. Annals of Saudi Medicine 20: 430-232.

17. Al Zahrani A (2005) Child Abuse and Neglect: Its Causes and Consequences in The Kingdom of Saudi Arabia. King Fhad National Library. Riyadh. Saudi Arabia.

18. Al Mahroos F (2007) Child Abuse and Neglect in the Arab Peninsula. Saud Medical Journal, 28: 241-248.

19. Al Brithen A (2006) Alcoholism and Domestic Violence in Saudi Society. Unpublished thesis. The University of Liverpool.

20. KFSH\&RC (2005) Pearls Journal. Published by the King Faisal Specialist Hospital and Research Centre. Riyadh. 